\title{
Extension of Heating and Pulse Power Capabilities at ASDEX Upgrade
}

\author{
Claus-Peter Käsemann ${ }^{\mathrm{a}}$, Arne Kallenbach ${ }^{\mathrm{a}}$, Jörg Stober ${ }^{\mathrm{a}}$, Jean-Marie Noterdaeme ${ }^{\mathrm{a}}$, Christian Hopf ${ }^{\mathrm{a}}$, \\ Nils Arden ${ }^{\mathrm{a}}$, Igor Goldstein ${ }^{\mathrm{a}}$ and the ASDEX Upgrade Team ${ }^{\mathrm{a}}$
}

${ }^{a}$ Max Planck Institute for Plasma Physics, Boltzmannstraße 2, 85748 Garching, Germany

\begin{abstract}
One of the biggest challenges for a fusion reactor with magnetic confinement is the controlled removal of the heating power. ASDEX Upgrade (AUG) is one of the leading experiments in this area and investigates integrated solutions that combine high heating power and wall materials suitable for reactors. A measure of the challenge to remove the power in the divertor region is given by the normalized output power. In AUG it is already $2 / 3$ of the value expected for a reactor. To increase it to the range of the values intended for ITER and DEMO, the present AUG program combines the rise of the central heating power by ECRH, ICRF and NBI with an enhancement and optimization of the power supply installation.
\end{abstract}

Keywords: ASDEX Upgrade; Plasma heating; Power supply; Reactive power compensation

\section{Introduction}

The Tokamak experiment ASDEX Upgrade (AUG) generates fusion plasmas to examine the physics of future fusion reactors. The research program is focused on the construction and operation of the ITER fusion experiment and the next step DEMO reactor. It is essential to understand plasma scenarios under reactor relevant conditions, possible with medium size experiments, in order to extrapolate it towards the size required for a power plant.

\section{Application}

An important topic of the research program is the controlled particle and energy transport from the core plasma to the edge. Thanks to the high heating power available, the core radiative fraction $\mathrm{P}_{\text {rad,main }} / \mathrm{P}_{\text {heat }}$ (i.e. the radiated power in the plasma core divided by the heating power) is already in the range of ITER and DEMO. The normalized heat flux in the divertor region $\mathrm{P}_{\mathrm{sep}} / \mathrm{R}$ (i.e. the power at the separatrix divided by the major plasma radius) is $10 \mathrm{MW} / \mathrm{m}$ for $2 \mathrm{~s}, 2 / 3$ of the value expected for a reactor and a world leading achievement [Fig. 1] [1].

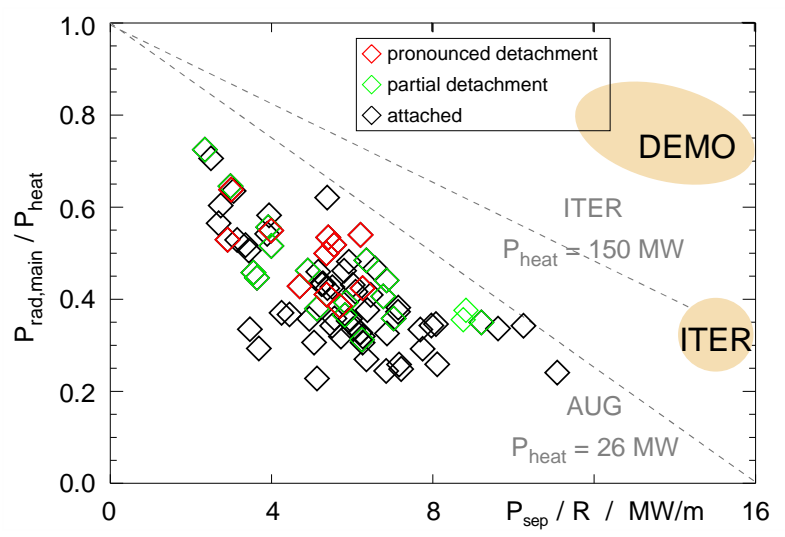

Fig. 1. Core radiation versus divertor power flux at ASDEX Upgrade

To go to even higher values for longer times, an extension of the heating power and power supply systems is required. The investment program combines the rise of the central heating power by Electron Cyclotron Resonance (ECRH) and Ion Cyclotron Resonance (ICRF) with an upgrade of the Neutral Beam Injection (NBI) and power supply installation, making the most of the limited energy available. The program is split into 5 topics:

- Enhancement of the ECRH from $2 \mathrm{MW} / 2 \mathrm{~s}+$ $4 \mathrm{MW} / 10 \mathrm{~s}$ to $8 \mathrm{MW} / 10 \mathrm{~s}$.

- Installation of two ICRF 3-strap antennas, followed by an additional third generator feeding the new antennas.

- Strengthening of the NBI injector 1 by modern Radio-Frequency (RF) sources and possibly later an increase of the accelerating voltage.

- Upgrade of the power supply for ohmic heating by a new high current converter.

- Installation of a 90 Mvar static reactive current compensation for the flywheel generator EZ4.

\section{Extension of Heating Power}

An overview of the AUG additional heating system is given in [Fig. 2].

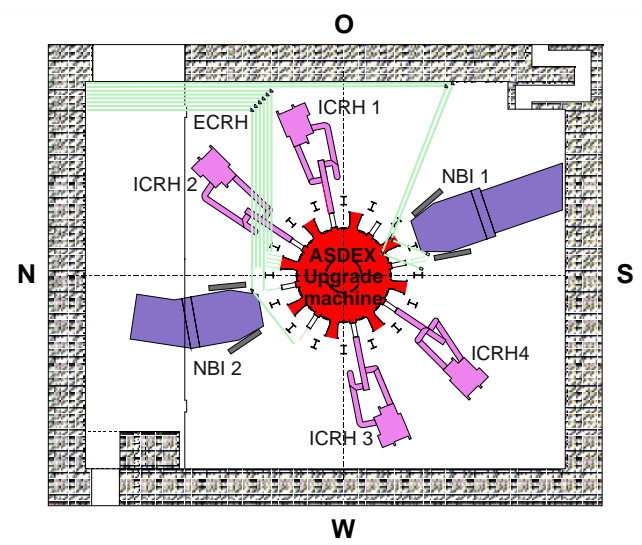

Fig. 2. Additional heating systems at ASDEX Upgrade 


\subsection{Electron Cyclotron Resonance Heating (ECRH)}

Plasma heating at ITER and DEMO will be dominated by electron heating. At current experiments (AUG, DIII-D, JET), heating of the ions by neutral beam injection is prevalent. Heating with microwaves at electron resonance frequency heats only the electrons and is thus most effective to increase the fraction of electron heating. At AUG a first system with $2 \mathrm{MW} / 2 \mathrm{~s}$ was in operation for two decades (closed down in 2016) pioneering heat pulse studies and NTM stabilization. Between 2006 and 2013 a 4 MW / 10 s system became operational which turned out to be very useful together with the internal $\mathrm{W}$ coating of the Tokamak. The pulse length and power of the initial $2 \mathrm{MW}$ system were limited compared to the design value of the AUG current flat-top time (10 s). In order to be able to study better the current diffusion and to extend the ECRH power in general, it has been decided to replace the initial system by another system with $4 \mathrm{MW} \mathrm{/} 10 \mathrm{~s}$ at $140 \mathrm{GHz}$ or $3.2 \mathrm{MW}$ at $105 \mathrm{GHz}$. Wherever appropriate, the new system follows the concept of the second ECRH system. Improvements encompass the cryogen-free magnets, the DC-heating of the cathodes and semiconductor based Body Modulators. After three years of installation, all auxiliaries are ready and the first Gyrotron is on site [Fig. 3]. Commissioning went on in September 2016, after the first Body Modulator arrived [2].

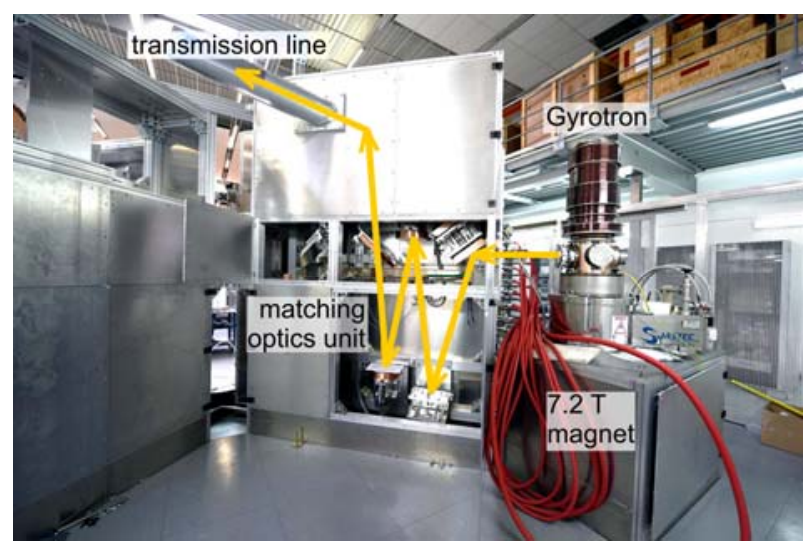

Fig. 3. First ECRH-3 Gyrotron with magnet, matching optics unit and transmission line

\subsection{Ion Cyclotron Resonance Frequency (ICRF)}

With the conventional antennas the use of ICRF was difficult in the tungsten covered torus of AUG. Tungsten eroded by ICRF-effects resulted in high radiation losses. Therefore the extension of the ICRF system relies on a completely newly designed type of 3-strap antennas, first tested in AUG in 2015. The RF image currents at the side limiters are reduced since the image current from the outer strap is compensated by that from the central strap. The RF electrical field component parallel to the stationary magnetic field $\mathrm{E}_{\|}$is decreased and tungsten sputtering at the limiters is reduced [Fig. 4].

Two antennas have been replaced by the new type in close cooperation with ASIPP (Hefei, China) and ENEA (Frascati, Italy). The experimental results proved the underlying antenna calculations and show tungsten content and tungsten sputtering that is at least a factor of
2 smaller compared to the old 2-strap antennas [3]. At the moment the four antennas are fed by four generators $<2 \mathrm{MW} / 30-120 \mathrm{MHz} / 10 \mathrm{~s}$. For the improved operation of the new antennas, the power in the outer straps has to be about half of the power in the central ones. Therefore the usable power of the new antennas is limited to $3 \mathrm{MW}$ [Fig. 5]. To fully make use of the antennas, the implementation of an additional generator already available on site - with 1.8 MW / 32-115 MHz / $9 \mathrm{~s}$ is currently being prepared. An additional $3 \mathrm{~dB}$ coupler and connection lines are necessary. New vacuum feedthroughs for the antenna feeding lines with higher dielectric strength would be advantageous [4].

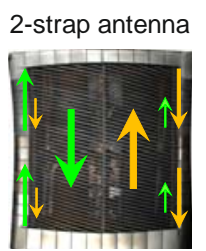

RF image currents

3-strap antenna
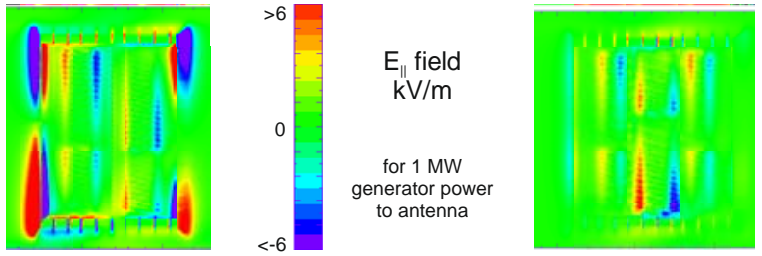

Fig. 4. RF image currents and the $\mathrm{E}_{\|}$-fields at side limiters of 2-strap and 3-strap ICRF antennas

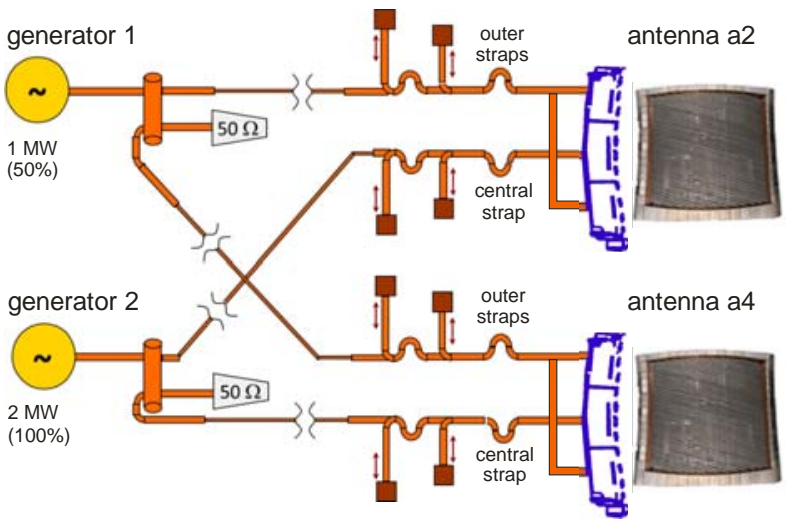

Fig. 5. ICRF connections between RF generators and new 3-strap antennas

\subsection{Neutral Beam Injection (NBI)}

Another important topic for high power discharges is the strengthening of the NBI. AUG runs two injectors with four neutral ion sources each. Every source provides an ion beam of $2.5 \mathrm{MW}$ in Deuterium and with the highest extraction voltage of $60 \mathrm{kV}$ (injector 1) and $93 \mathrm{kV}$ (injector 2). While the older injector 1 still operates with arc plasma sources, injector 2 has RF sources. The RF sources are an IPP development. They proved to be substantially more reliable and provide fast feedback control of the extracted current [5]. Ageing of the arc source components put the long-term availability at risk. Therefore the existing arc sources will be substituted by modern RF sources which can be mounted on the existing accelerator grid assemblies [Fig. 6]. The solid state RF generator chosen provides higher power 
efficiency and shows much improved matching properties compared to the conventional oscillator generators [6]. The RF generators have already been delivered and commissioning and testing of the first generator at a test bench was successful. In parallel procurement of the sources and infrastructure components started.

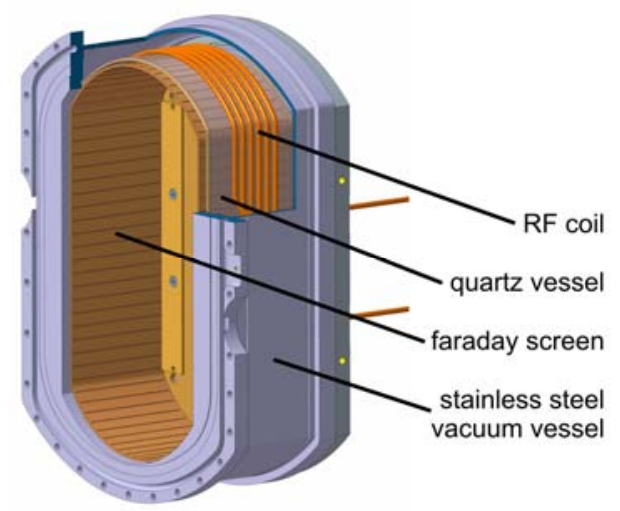

Fig. 6. The ASDEX Upgrade RF neutral beam plasma source

\section{Enhancement of Power Supplies}

The operation of AUG relies on three large flywheel generators (EZ2, EZ3 and EZ4). These generators feed the pulsed power supply system for the magnetic confinement (high current) and additional heating (high voltage) of the plasma with stored energies up to 2750 MJ. 17 high current (HC) thyristor converters with an installed pulsed power of about 600 MVA feed the copper magnet coils that induce the plasma current and provide positioning, shaping and ohmic heating of the plasma. Currents up to $45 \mathrm{kA}$ at voltage levels up to $3 \mathrm{kV}$ for $10 \mathrm{~s}$ are possible. For the heating and the current drive of the plasma by NBI, ECRH and ICRF, 28 high voltage (HV) modules with an installed power of about $95 \mathrm{MW}$ are available. The modules provide voltages up to $140 \mathrm{kV}$ with currents up to $100 \mathrm{~A}$ [Fig. 7] [7].

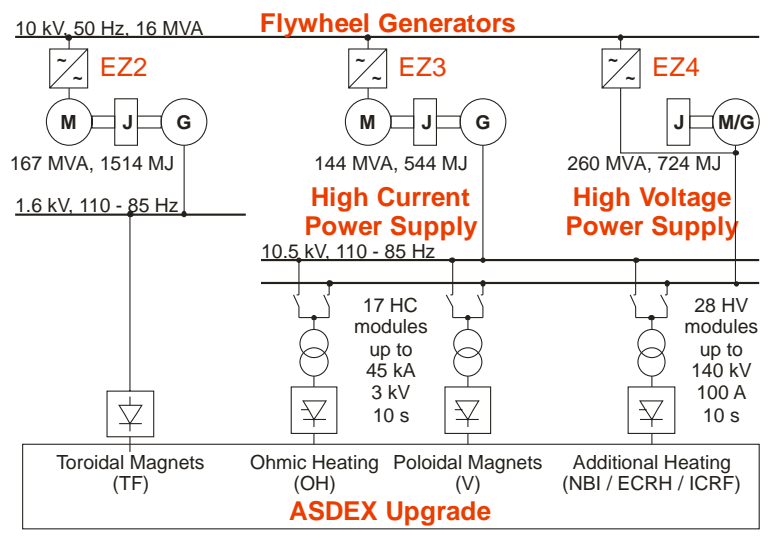

Fig. 7. Experimental power supply network

\subsection{High Current Converter}

Due to the successful program of AUG the high current converters come to their limits. At the same time the risk of failure increases because of ageing. At the moment all converters are in use and thus the area of operations is fixed. Low power, high density discharges of AUG are limited by the $\mathrm{OH}$ transformer flux. Therefore a new thyristor converter group is planned. In combination with an existing converter, the $\mathrm{OH}$ supply will be increased from $+/-40 \mathrm{kA} / 5 \mathrm{~s}$ to $+/-45 \mathrm{kA} / 10 \mathrm{~s}$. At the same time, the so called "neutral control" of the star point current of the converter transformer allows for a substantial reduction of the reactive power demand under partial-load operation [Fig. 8] [8]. Integration work into the AUG power supply network and preparation of the technical specification is already in progress.

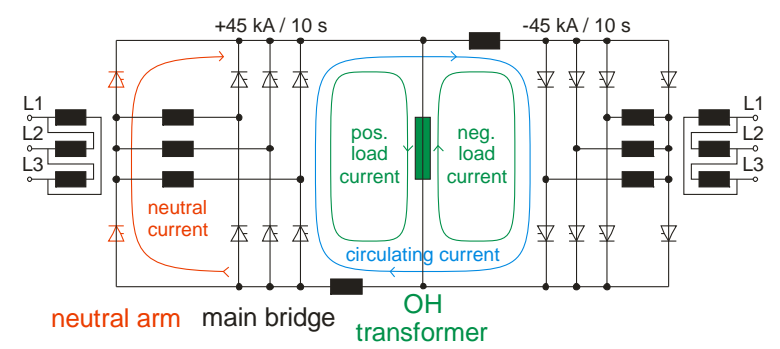

Fig. 8. Reactive power reduction by "neutral control"

\subsection{Reactive Power Compensation}

The high inductive voltage necessary to ignite the plasma and to ramp up the currents in the copper made poloidal field coils results in a high reactive power demand of the high current converters during plasma flattop. The firing angle of the thyristors has to be strongly delayed and the power factor of e.g. generator EZ3 drops from $\cos \varphi=0.6 \ldots 0.8$ during ignition down to $0.2 \ldots 0.3$ during plasma flattop. To optimize the energy consumption and to satisfy the power demand, a 8x 15 Mvar reactive power compensation (RPC) was installed at flywheel generator EZ3 in 2001. The stator current of the generator could substantially be reduced by a factor of two during the ramp-up phase of an $800 \mathrm{kA}$ plasma pulse [9]. The RPC is choked and additional damping resistors are connected in parallel to the filter reactors. To prevent generator overload in case of a sudden RPC tripping, the maximum peak power of the generator should not be exceeded. Therefore operation was limited to 6 RPC modules and the gain is not so much a higher peak power, but an improved use of the available energy and thus an extension of the possible pulse length. In 2014 the two spare RPC modules of EZ3 were connected to generator EZ4 in order to test the system stability by switching 30 Mvar reactive power to a converter driven, self-excited generator system. The results are very promising. The difference between the required load current (red trace) and the provided generator current (green trace) due to the reactive power compensation can be seen in [Fig. 9]. To make best use of the existing installation, the extended compensation for the EZ3 and EZ4 network will consist of 2x 15 Mvar and 2x 30 Mvar modules each. 

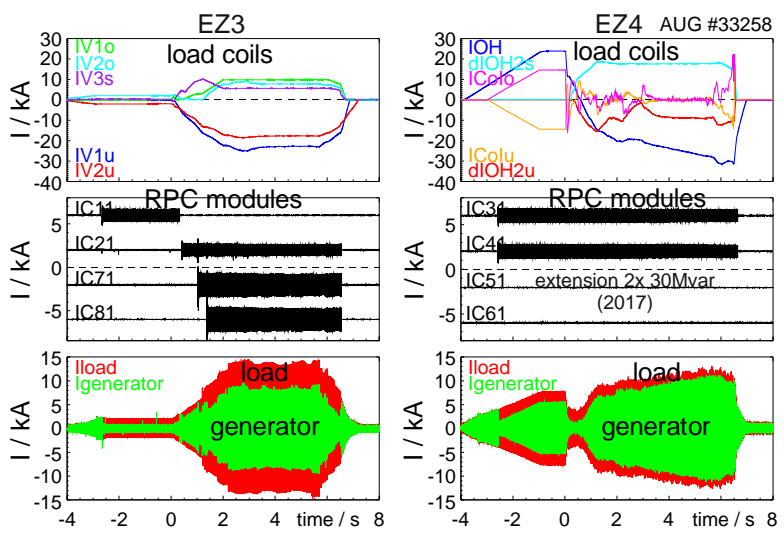

Fig. 9. Reactive power reduction at flywheel generators EZ3 and EZ4

\section{Present State and Findings}

At the moment plasma pulses with up to $26 \mathrm{MW}$ heating power are possible. Discharge \#33258 in March 2016 deposited a heating energy of $\mathrm{E}_{\mathrm{inj}}=100 \mathrm{MJ}$ into the plasma at a plasma current of 1.2 MA [Fig. 10]. The normalized heat flux was $P_{\text {sep }} / R=9 \mathrm{MW} / \mathrm{m}$ and a Divertor detachment with $23 \mathrm{MW}$ of heating power was realized by combined injection of nitrogen and argon. A technical description of a very similar pulse is given in [10]. The experiments will go on for the enhancement of the detachment power.

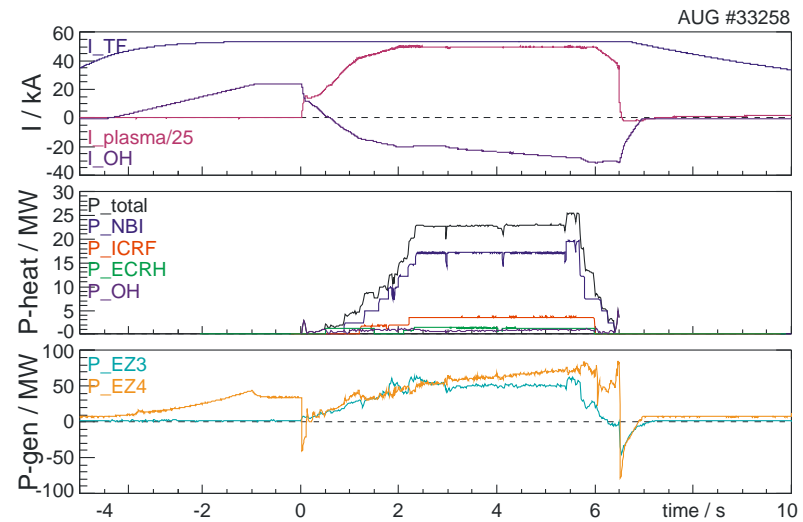

Fig. 10. AUG discharge with $\mathrm{P}_{\text {sep }} / \mathrm{R}$ up to $9 \mathrm{MW} / \mathrm{m}$, $100 \mathrm{MJ}$ heating energy and 1.2 MA plasma current

\section{Conclusion and Future Exploitation}

AUG operation and planned extensions during the Horizon 2020 research program follow the requirements of Mission 1 and 2 of the EU Roadmap towards a fusion power reactor [Fig. 11].

\begin{tabular}{|c|c|c|c|c|c|c|}
\hline \multirow{4}{*}{$\begin{array}{l}\text { Mission 1: } \\
\text { Plasma } \\
\text { Operation }\end{array}$} & 2014 & 2015 & 2016 & 2017 & 2018 & 2019 \\
\hline & \multicolumn{6}{|l|}{ ECRH III } \\
\hline & \multicolumn{6}{|c|}{ Internal Coils "StauchiMiPs " } \\
\hline & \multicolumn{2}{|c|}{ ICRH antenna } & \multicolumn{4}{|c|}{ " Compatibility of ICRH with tungsten wall " } \\
\hline \multirow{3}{*}{$\begin{array}{l}\text { Mission 2: } \\
\text { Exhaust }\end{array}$} & \multicolumn{6}{|c|}{ High power and pulse length Deiwio relevant exhaust " } \\
\hline & W wall & & \multicolumn{4}{|c|}{ "* Qualification of reactor relevant materials "* } \\
\hline & Design & Cor & Iction / In & ation & 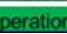 & \\
\hline
\end{tabular}

Fig. 11. Schedule for AUG extensions and operation during the Horizon 2020 EU program

The complete ECRH installation with four additional Gyrotrons should be available for the 2017/18 experimental campaign and will be the most powerful
ECRH system on a Tokamak experiment worldwide. The new system allows for more flexible profile tailoring while maintaining central heating, resulting in more current drive and higher $\mathrm{P}_{\text {sep }} / \mathrm{R}$. After completion of the ICRF upgrade in 2018, the installed maximum RF generator power will be increased from $8 \mathrm{MW}$ to $10 \mathrm{MW}$ while the tungsten production will be kept low. Assembly and installation of the NBI RF sources is scheduled for 2018. This upgrade will increase the reliability of NBI, reduces the risk of long downtimes and is necessary for a possible later increase of the accelerating voltage in order to achieve a more central power deposition into the plasma. The new high current power supply installation should be finished by 2019 and will increase the $\mathrm{OH}$ transformer flux and pulse length. The upgrade of the EZ4 reactive power compensation to 90 Mvar will be commissioned in 2016 and will improve the usable power at AUG.

Altogether, with these measures the heating and pulse power capabilities of AUG will be increased towards achieving a stationary behavior of the current profile and plasma wall interaction under reactor relevant conditions. The total heating power will be in the range of $34 \mathrm{MW}$ and the phase of high heating power will significantly be extended to more than $5 \mathrm{~s}$. This will allow a normalized heat flux $\mathrm{P}_{\text {sep }} / \mathrm{R}$ up to $15 \mathrm{MW} / \mathrm{m}$, in the range of the values intended for ITER and DEMO. Further on, the availability of the installation will be improved, resulting in a more efficient operation close to the limits of the systems.

\section{Acknowledgments}

This work has been carried out within the framework of the EUROfusion Consortium and has received funding from the Euratom research and training programme 2014-2018 under grant agreement No 633053. The views and opinions expressed herein do not necessarily reflect those of the European Commission.

\section{References}

[1] A. Kallenbach et al., Nuclear Fusion 55 (2015) 053026

[2] J. Stober et al., EPJ Web of Conferences 87 (2015) 02004

[3] V. Bobkov et al., Plasma Physics and Controlled Fusion 59 (2017) 014022

[4] H. Fünfgelder et al., Fusion Engineering and Design 123 (2017) 40-46

[5] E. Speth et al., Fusion Engineering and Design 46 (1999) 383-388

[6] C. Hopf, EUROfusion report EFDA_D_2CXQWS (2016)

[7] C.-P. Käsemann et al., EEEIC (2015) 237-242

[8] C.-P. Käsemann et al., Fusion Engineering and Design 66-68 (2003) 1133-1137

[9] C. Sihler et al., Engineering and Design 66-68 (2003) 1139-1142

[10] A. Kallenbach et al., Nuclear Fusion 52 (2012) 122003 